\title{
ANALISIS POTENSI PEMBANGKIT LISTRIK TENAGA MIKRO HYDRO PADA ANAK SUNGAI DI BULUNGAN
}

\author{
Wibowo Romadhoni, Dady Sulaiman*, Purnama
}

Jurusan Fisika Universitas Kaltara, Kabupaten Bulungan Provinsi Kalimantan Utara

Email*: dadysulaiman92@gmail.com

\begin{tabular}{c|c|c|c}
\hline Diterima 19 Februari 2021 & Direvisi 16 April 2021 & Disetujui 3 Mei 2021 & Dipublikasikan 10 Mei 2021 \\
\hline \multicolumn{4}{c}{ https://doi.org/10.33369/jkf.4.1.61-66 } \\
\hline
\end{tabular}

\begin{abstract}
ABSTRAK
Energi listrik merupakan energi utama masyarakat pada era globalisasi. Perusahaan Listrik Nasional (PLN) masih belum bisa menjangkau daerah - daerah terpencil khususnya daerah kabupaten Bulungan yang memiliki banyak daerah terpencil. Masalah ini dapat diatasi dengan memanfaatkan anak sungai yang ada di kabupaten Bulungan sebagai sumber energi listrik. Penelitian ini dimulai dengan survey memilih 20 titik anak sungai yang akan diteliti di kabupaten Bulungan. Selanjutnya pengambilan data yaitu luas penampang sungai, kecepatan aliran sungai, dan tinggi jatuh air. Data ini akan dianalisis dengan menggunakan rumus agar memperoleh nilai daya teoritis yang dihasilkan oleh masing - masing sungai yang telah ditentukan. Hasil penelitian inimenunjukkan diantara 20 anak sungai yang diteliti hanya 2 anak sungai yang memiliki potensi yaitu sungai 9 dengan daya $5,5 \mathrm{~kW}$ dan sungai 14 dengan daya $8,5 \mathrm{~kW}$. Hasil penelitian ini dapat dikembangkan lagi agar dapat bermanfaat bagi pengembangan daerah - daerah terpencil yang tidak terjangkau PLN.
\end{abstract}

Kata kunci : Daya, Energi Terbarukan, PLTMH

\section{ABSTRACT}

Electrical energy is the main energy of society in the era of globalization. Perusahaan Listrik Nasional (PLN) is still unable to reach remote areas, especially the Bulungan district which has many remote areas. This problem can be overcome by utilizing tributaries in Bulungan district as a source of electrical energy. This research began with a survey selecting 20 tributary points to be studied in Bulungan district. Furthermore, data collection was the crosssectional area of the river, river flow velocity, and water fall height. This data was analyzed using a formula in order to obtain the theoretical power value generated by each predetermined river. The results of this study indicatde that among the 20 tributaries studied, only 2 tributaries have potential, namely river 9 with a power of $5.5 \mathrm{~kW}$ and river 14 with a power of $8.5 \mathrm{~kW}$. It is hoped that the results of this research can be further developed so that they can be useful for the development of remote areas that are not reached by PLN.

Keyword: PLTMH, Power, Renewable Energy,

\section{PENDAHULUAN}

Energi listrik merupakan energi utama masyarakat pada era globalisasi. Peningkatan kebutuhan listrik meningkat sejalan dengan meningkatnya perkembangan teknologi (1-4). Ada banyak jenis sumber energi yang dapat digunakan untuk memenuhi kebutuhan listrik masyarakat seperti bahan bakar fosil (solar, minyak gas alam, batu bara dll) atau memanfaatkan energi baru dan terbarukan (surya biomassa, dan air) $(1,2)$. Sumber bahan bakar fosil semakin menipis sehingga pengembangan sumber energi terbarukan lebih diutamakan $(5,6)$. Umumnya penggunaan bahan bakar fosil sebagai sumber energi dikelola oleh Perusahaan Listrik Nasional (PLN) yang belum bisa menjangkau daerah - daerah terpencil $(1,2,7,8)$. Masalah ini dapat diselesaikan dengan membangun sumber energi listrik sederhana seperti Pembangkit Listrik Tenaga Mikro Hidro (PLTMH) $(1,8-10)$.

PLTMH adalah pembangkit listrik dengan menfaatkan air sebagai tenaga untuk menghasilkan listrik dengan skala kecil. Pembangkit listrik ini merupakan pembangkit yang ramah lingkungan (3,11). Sumber energi gerak dari PLTMH ini memanfaatkan debit alir dan 
ketinggian terjunan air (head) yang bisa ditemukan saluran irigasi, anak sungai dan air terjun $(10,12,13)$. Pembangkit Listrik Tenaga Air dibagi menjadi 6 jenis berdasarkan daya yang dihasilkan Tabel 1 .

Tabel 1. Klasifikasi PLTA (9)

\begin{tabular}{lcc}
\hline No & Jenis PLTA & Kapasitas \\
\hline $\mathbf{1}$ & PLTA Besar & $>100 \mathrm{MW}$ \\
$\mathbf{2}$ & PLTA Menengah & $(15-100) \mathrm{MW}$ \\
$\mathbf{3}$ & PLTA Kecil & $(1-15) \mathrm{MW}$ \\
$\mathbf{4}$ & PLTM (mini hidro) & $100 \mathrm{~kW}-1 \mathrm{MW}$ \\
$\mathbf{5}$ & PLTMH (mikro hidro) & $(5-100) \mathrm{kW}$ \\
$\mathbf{6}$ & Piko Hidro & $<5 \mathrm{~kW}$
\end{tabular}

Daya yang dihasilkan oleh PLTMH berada dalam rentang $5 \mathrm{~kW}-100 \mathrm{~kW}$ (1). Komponen utama untuk membuat PLTMH adalah sumber air, bak penenang, penstock, turbin, dan generator $(1,10,14)$. Prinsip kerja PLTMH adalah dengan memanfaatkan air untuk menggerakan turbin, turbin berfungsi untuk menghasilkan energi gerak, energi gerak ini dikonversi menjadi energi listrik dengan bantuan generator (7,9,10,13). PLTMH ini memiliki beberapa keunggulan, yaitu ramah lingkungan, renewable energy, tahan lama, biaya operasional yang minimalis $(4,14)$ dan sesuai untuk daerah pedesaan $(5,15)$.

Kabupaten Bulungan merupakan ibu kota provinsi Kalimantan utara (KALTARA). Daerah ini memiliki sungai kayan yaitu salah satu sungai terbesar di KALTARA. Sungai ini memiliki banyak anak sungai yang tersebar hampir disemua area kabupaten Bulungan. Beberapa anak-anak sungai yang besar telah dimanfaatkan sebagai sumber energi di beberapa desa. Penelitian ini bertujuan untuk mencari potensi PLTMH dari anak-anak sungai yang berada di sekitar pemukiman yang kekurangan pasokan listrik atau tidak terjangkau oleh PLN.

\section{METODE PENELITIAN}

Tahapan penelitian ini ditunjukkan dengan diagram alir penelitian pada Gambar 1.

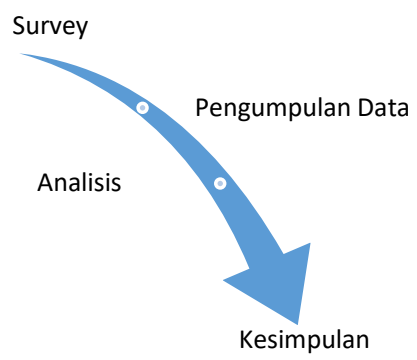

Gambar 1. Diagram Alir Penelitian

Penelitian ini dibagi menjadi 4 tahap yang masing - masingnya akan dijelaskan berikut.

\subsection{Survey}

Pada tahap ini akan dilakukan survey untuk menentukan anak - anak sungai mana saja yang memiliki potensi PLTMH. Pemilihan lokasi ini memiliki beberapa kriteria yaitu dekat dengan pemukiman, mudah dijangkau dan memiliki arus dan titik jatuh air. Pada Gambar 2 dapat dilihat 20 anak sungai yang memiliki potensi PLTMH.

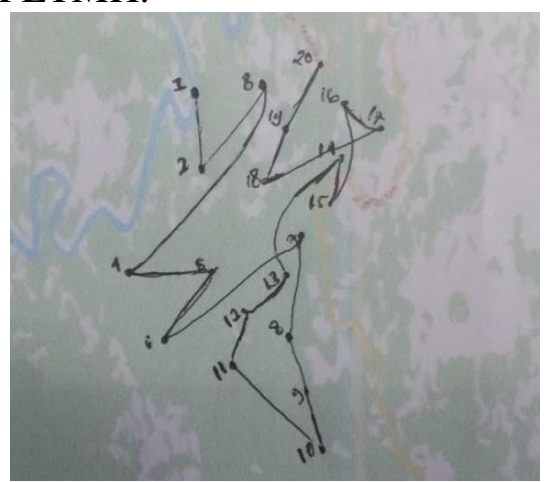

Gambar 2. 20 titik lokasi pengambilan data di kabupaten Bulungan 


\subsection{Pengumpulan Data}

Setelah menentukan lokasi penelitian, langkah selanjutnya adalah pengambilan data. Adapun data - data yang akan diambil adalah sebagai berikut.

a. Luas Penampang Sungai

Luas penampang sungai dihitung dengan Rumus 1. Data yang diambil adalah lebar sungai dan kedalamannya di beberapa titik dimana pada penelitian ini ada 10 titik.

$$
A=\frac{L_{1} D_{1}+L_{2} D_{2}+L_{2} D_{2}+\cdots . .+L_{n} D_{n}}{n}
$$

dengan A adalah luas $\left(m^{2}\right)$, L adalah lebar $(m)$, dan D adalah kedalaman $(m)(16)$.

b. Kecepatan aliran air

Pengukuran kecepatan aliran air menggunakan metode apung yaitu dengan cara mengapungkan suatu benda (botol) sampai jarak yang telah ditentukan $(6 \mathrm{~m})$ dan mencatat waktu tempuh benda tersebut hingga sampai di titik yang dituju.

c. Tinggi jatuh air

Pada setiap titik terdapat titik jatuh air alami untuk menggerakkan turbin. Data ini digunakan untuk mencari daya yang dihasilkan oleh aliran sungai tersebut.

\subsection{Analisis}

Setelah pengumpulan data, langkah selanjutnya adalah analisis data tersebut. Hasil akhir dari analisis ini adalah menemukan daya teoritis yang dihasilkan oleh anak - anak sungai tersebut yang dituliskan pada persamaan 2 .

$$
P=\rho g Q H
$$

Debit air dirumuskan sebagai berikut

$$
Q=A v
$$

dengan $\mathrm{P}$ adalah daya teoritis (Watt), $\rho$ adalah massa jenis air $\left(\mathrm{kg} / \mathrm{m}^{3}\right), g$ adalah percepatan gravitasi $\left(9,8 \mathrm{~m} / \mathrm{s}^{2}\right), H$ adalah tinggi jatuh air $(\mathrm{m}), Q$ adalah debit $\left(\mathrm{m}^{3} / \mathrm{s}\right), A$ adalah luas penampang sungai $\left(\mathrm{m}^{2}\right)$, dan $v$ adalah kecepatan aliran sungai $(\mathrm{m} / \mathrm{s})(16)$.

\subsection{Kesimpulan}

Langkah terakhir adalah penarikan kesimpulan berdasarkan daya yang dikeluarkan pada setiap titik yang telah ditentukan.

\section{HASIL DAN PEMBAHASAN}

Setelah melakukan pengambilan data pada 20 anak sungai di kabupaten Bulungan diperoleh hasil pada Tabel 2 .

Tabel 2. Hasil Analisis Data Debit, Kecepatan dan Daya

\begin{tabular}{ccccc}
\hline Sungai & $\begin{array}{c}\text { Lebar Sungai } \\
(\mathbf{m})\end{array}$ & $\begin{array}{c}\text { Debit } \\
\left(\boldsymbol{m}^{\mathbf{3}} \boldsymbol{s}\right)\end{array}$ & $\begin{array}{c}\text { Kecepatan Alir } \\
(\boldsymbol{m} / \boldsymbol{s})\end{array}$ & $\begin{array}{c}\text { Daya } \\
(\text { Watt })\end{array}$ \\
\hline $\mathbf{1}$ & 4 & 115.2 & 72 & 564.48 \\
\hline $\mathbf{2}$ & 5 & 187.2 & 72 & 1100.74 \\
\hline $\mathbf{3}$ & 6 & 178.2 & 59.4 & 1397.09 \\
\hline $\mathbf{4}$ & 5 & 300 & 60 & 588.00 \\
\hline $\mathbf{5}$ & 5 & 90 & 60 & 176.40 \\
\hline $\mathbf{6}$ & 6 & 324 & 90 & 635.04 \\
\hline $\mathbf{7}$ & 3.6 & 97.2 & 54 & 285.77 \\
\hline $\mathbf{8}$ & 3.6 & 171.72 & 95.4 & 504.86 \\
\hline $\mathbf{9}$ & 7.2 & 1879.2 & 174 & 5524.85 \\
\hline $\mathbf{1 0}$ & 4.5 & 194.4 & 72 & 762.05 \\
\hline $\mathbf{1 1}$ & 5.2 & 194.688 & 72 & 1144.77 \\
\hline $\mathbf{1 2}$ & 6 & 178.2 & 59.4 & 523.91 \\
\hline
\end{tabular}




\begin{tabular}{ccccc}
\hline Sungai & $\begin{array}{c}\text { Lebar Sungai } \\
(\mathbf{m})\end{array}$ & $\begin{array}{c}\text { Debit } \\
\left(\boldsymbol{m}^{\mathbf{3}} / \boldsymbol{s}\right)\end{array}$ & $\begin{array}{c}\text { Kecepatan Alir } \\
(\boldsymbol{m} / \boldsymbol{s})\end{array}$ & $\begin{array}{c}\text { Daya } \\
(\text { Watt) }\end{array}$ \\
\hline $\mathbf{1 3}$ & 7 & 294 & 60 & 1728.72 \\
\hline $\mathbf{1 4}$ & 60 & 1728 & 57.6 & 8467.20 \\
\hline $\mathbf{1 5}$ & 5.3 & 159 & 60 & 467.46 \\
\hline $\mathbf{1 6}$ & 6.3 & 234.738 & 69 & 920.17 \\
\hline $\mathbf{1 7}$ & 60 & 2916 & 54 & 2857.68 \\
\hline $\mathbf{1 8}$ & 5.4 & 340.2 & 90 & 1000.19 \\
\hline $\mathbf{1 9}$ & 12 & 864 & 72 & 4233.60 \\
\hline $\mathbf{2 0}$ & 3.2 & 184.32 & 96 & 722.53
\end{tabular}

Data pada tabel 2 di atas diilustrasikan dalam bentuk Grafik di Gambar 3 dan 4 untuk mempermudah penjelasannya.

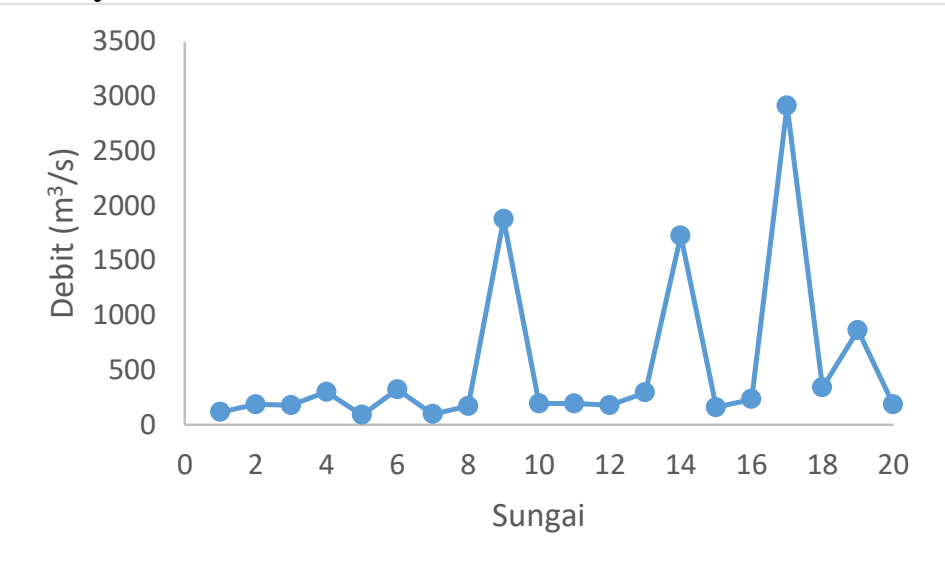

Gambar 3. Grafik Perbandingan Debit

Hasil perhitungan debit berdasarkan luas penampang dan kecepatan aliran sungai dapat dilihat pada Gambar 3. Berdasarkan gambar tersebut, mayoritas sungai memiliki debit yang kecil yakni dibawah 500. Hanya ada 4 anak sungai yang memiliki debit di atas 500 yaitu sungai 9 $(1879,2)$, sungai 14 (1728), sungai 17 (2916) dan sungai 19 (864).

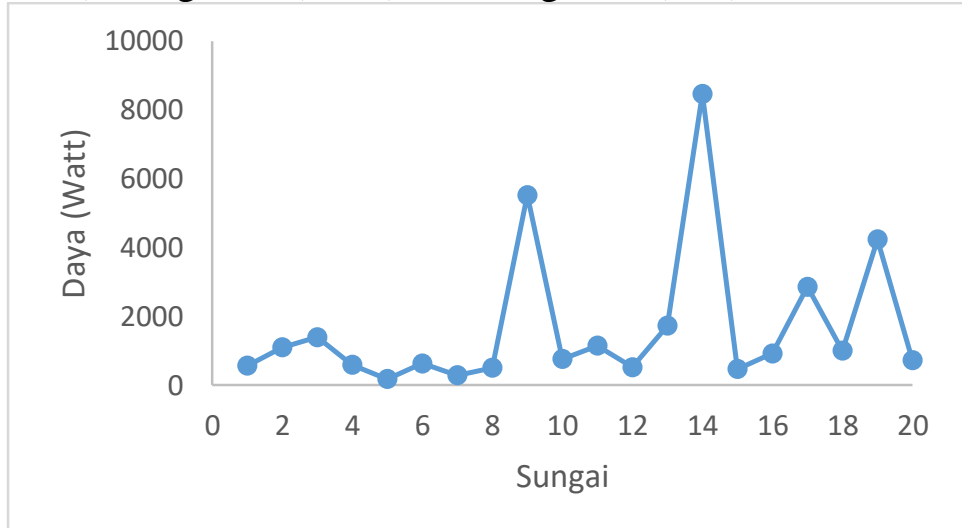

Gambar 4. Grafik Perbandingan Daya

Gambar 4 menampilkan hasil pperhitungan daya menggunakan rumus 2. Berdasarkan grafik tersebut rata-rata daya yang dihasilkan pada setiap titik hanya kisaran $2 \mathrm{~kW}$ sementara syarat daya yang dihasilkan agar dapat dikatakan memiliki potensi PLTMH adalah $5 \mathrm{~kW}$. Anak sungai yang masuk dalam kategori ini hanya anak sungai 9 dan 14 dengan nilai daya $5,5 \mathrm{~kW}$ dan $8,5 \mathrm{~kW}$ serta yang mendekati syarat PLTMH adalah anak sungai 17 dan 19 dengan nilai daya 2,9 kW dan 4,2 $\mathrm{kW}$.

Berdasarkan hasil perhitungan dan analisis dapat diambil kesimpulan dari 20 anak sungai yang telah diuji di kabupaten Bulungan, hanya 2 anak sungai yang memiliki potensi PLTMH yaitu sungai 9 dan sungai 14 . Sungai 9 yaitu sungai Ruhui Rahayu 2 berada di daerah/ desa Ruhui 
Rahayu (SP5) kecamatan Tanjung Palas Utara. Sungai ini memiliki lebar kurang lebih $7 \mathrm{~m}$ dan berada tidak jauh dari sungai utama sehingga memiliki aliran air yang laju. Sementara sungai 14 yang berada di desa metadau memiliki ukuran lebar yang palig besar yaitu $60 \mathrm{~m}$ yang bisa dianggap sebagai salah satu sungai besar di kabupaten bulungan selain sungai kayan. Hal ini membuat sungai 14 memiliki potensi yang besar sebagai PLTMH.

\section{SIMPULAN DAN SARAN}

4.1 Simpulan

Berdasarkan hasil analisis dan pembahasan diperoleh hasil sungai 9 (Sungai Ruhui Rahayu (SP5) sungai 2) dan sungai 14 (Sungai Metadau) memiliki potensi sebagai sumber PLTMH di daerah Bulungan dengan nilai daya teoritis $5,5 \mathrm{~kW}$ dan $8,5 \mathrm{~kW}$, terutama sungai 14 karena memiliki ukuran terlebar dibandingkan sungai lainnya.

\subsection{Saran}

Diharapkan untuk penelitian selanjutnya agar memperluas titik pengambilan data agar memperoleh hasil yang lebih baik dan dapat dikembangkan lebih lanjut. Data yang dihasil pada penelitian ini hanya sebatas perhitungan teoritis dengan mengabaikan banyak hal seperti efisiensi mesin, keadaan sungai pada iklim yang berbeda dan lain - lain.

\section{DAFTAR PUSTAKA}

1. Setiawan Wie D, Imam Agung A. Perencanaan Dan Implementasi Prototipe Pembangkit Listrik Tenaga Mikro Hidro ( PLTMH ) PERENCANAAN DAN IMPLEMENTASI PROTOTIPE PEMBANGKIT LISTRIK TENAGA MIKRO HIDRO (PLTMH). J Tek Elektro. 2018;7(1):31-36.

2. Hanggara I, Irvani H. POTENSI PLTMH (PEMBANGKIT LISTRIK TENAGA MIKRO HIDRO) DI KECAMATAN NGANTANG KABUPATEN. J Reka Buana. 2017;2(2):149_ 155.

3. Anaza SO, Abdulazeez MS, Yisah YA, Yusuf YO, Salawu BU, Momoh SU. Micro HydroElectric Energy Generation- An Overview. Am J Eng Res. 2017;6(2):5-12.

4. Córdoba AT, Reina DG, Gata PM. An Evolutionary Computational Approach for Designing Micro Hydro Power Plants. Energies. 2019;12:25.

5. Erinofiardi, Gokhale P, Date A, Akbarzadeh A, Bismantolo P, Suryono AF, et al. A review on micro hydropower in Indonesia. Energy Procedia [Internet]. 2017;110:316-21. Available from: https://doi.org/10.1016/j.egypro.2017.03.146

6. Sulaiman D, Romadhoni W, Arlina. Analisis Karakteristik Kelistrikan Campuran Belimbing Wuluh dan Jeruk Lemon Sebagai Sumber Listrik. J Teor dan Apl Fis. 2020;8(2):63-8.

7. Kriswanto, Djufri SU. Perhitungan Daya Output PLTMH di Jalan Bintara Sungai Duren Jambi. J Electr Power Control Autom [Internet]. 2019;2(1):11-15. Available from: https://doi.org/10.33087/jepca.v2i1.24

8. Suyanta, Puspitasari E, Maskuri. STUDI POTENSI DAN PEMANFAATAN ALIRAN AIR SUNGAI UNTUK PLTMH MENGGUNAKAN KINCIR SUDU BERSIRIP. J Ilm Teknol FST Undana. 2018;12(2):32-9.

9. Hasanudin L, Lolok A, Balaka R, Kadir, Ode Amrul Hasan L, Aminur, et al. ANALISIS POTENSI DAYA PEMBANGKIT LISTRIK TENAGA MIKROHIDRO (PLTMH) PADA SUNGAI BONE DI KECAMATAN PASIR PUTIH KABUPATEN MUNA. In: SEMINAR NASIONAL TEKNOLOGI TERAPAN INOVASI DAN REKAYASA (SNT2IR). 2019. p. 304-315.

10. Saputra IWB, Weking AI, Jasa L. Mikro Hidro (PLTMH) Menggunakan Kincir Overshot Wheel. Makal Ilm Tek Elektro. 2017;16(2):48-54.

11. Malhan P, Mittal M. Evaluation of different statistical techniques for developing cost correlations of micro hydro power plants. Sustain Energy Technol Assessments [Internet]. 2021;43:100904. Available from: https://doi.org/10.1016/j.seta.2020.100904 
12. Supu I, Jambonada N, Hakim, Indirahasiti, Sulastri D, Jaya I, et al. PROTOTIPE PEMBANGKIT LISTRIK MIKROHIDRO (PLTMh) DENGAN MEMANFAATKAN ALIRAN SUNGAI LATUPPA. J Din. 2016;7(2):42-48.

13. Jawadz URH, Prasetijo H, Purnomo WH. STUDI POTENSI PEMBANGKIT LISTRIK TENAGA MIKRO HIDRO (PLTMH) DI ALIRAN SUNGAI DESA KEJAWAR BANYUMAS. Din Rekayasa. 2019;15(1):11-24.

14. Gudukeya LK, Mbohwa C. Improving the Efficiencies of Pelton Wheel in Micro-Hydro Power Plants. In: Proceedings of the International Conference on Industrial Engineering and Operations Management. 2017. p. 1089-1100.

15. Purnama A. PEMBANGKIT LISTRIK TENAGA MIKROHIDRO Studi Kasus: PLTMH Minggir pada saluran irigasi Minggir di Padukuhan Klagaran Desa Sendangrejo Kecamatan Minggir Kabupaten Sleman. J UNSA Prog. 2011;10(15):93-111.

16. Norhadi A, Marzuki A, Wicaksono L, Yacob RA. STUDI DEBIT ALIRAN PADA SUNGAI ANTASAN KELURAHANSUNGAI ANDAI BANJARMASIN UTARA. J POROS Tek. 2015;7(1):7-14. 